\title{
Review
}

\section{The Development and Bio-applications of Multifluid Electrospinning}

\author{
Menglong Wang ${ }^{1}$, Deng-Guang Yü ${ }^{1, *}$, Xiaoyan Li ${ }^{1}$, Gareth R Williams ${ }^{2}$ \\ ${ }^{1}$ School of Materials Science \& Engineering, University of Shanghai for Science and Technology, Shanghai 200093, China \\ ${ }^{2}$ UCL School of Pharmacy, University College London, 29-39 Brunswick Square, London WC1N 1AX, UK
}

\author{
ARTICLE INFO \\ Article History \\ Received 28 February 2020 \\ Accepted 19 May 2020 \\ Keywords \\ Electrospinning \\ multifluid electrospinning \\ bio-applications \\ core-shell nanofibers \\ Janus nanofibers
}

\begin{abstract}
Electrospinning is a potent "top-down" nanofabrication method and has been explored by many researchers in recent decades because it is an efficient, versatile, simple, and low-cost route to prepare nanofibers. Nanofiber membranes generated by electrospinning have been used in various fields including tissue engineering, wound dressing, biosensing, theranostics, and functional textiles. Here we summarize the development of multifluid electrospinning processes, including coaxial, Janus and triaxial electrospinning, and the applications of these techniques. Complex nanostructures prepared by multifluid electrospinning are considered. The key parameters that affect the electrospinning process are introduced, and a discussion of both equipment and solution parameters is presented.
\end{abstract}

(C) 2020 The Authors. Published by Atlantis Press SARL.

This is an open access article distributed under the CC BY-NC 4.0 license (http://creativecommons.org/licenses/by-nc/4.0/).

\section{INTRODUCTION}

Along with the booming of nature science, bioscience has been explored widely and developed fast. Along with the knowledge from macro to micro, and further deeper to nano, nanotechnology has been developed fast, such as electrospinning, which uses a "top-down" way to produce nanomaterials. Nanomaterials have gradually entered the lives of people. Nanomaterials, including nanofibers and nanoparticles, have been explored in myriad fields, such as drug delivery systems [1], sewage treatment [2,3], material reinforcing [4], tissue engineering [5], catalysis [6], sensors [7,8], filtration membranes $[9,10]$, osmosis membranes [11,12], and electrolytes [13] inter alia.

Electrospinning is a membrane preparation technology which has developed rapidly in recent decades. As the sister technology of electrospraying [14-17], takes advantage of the interactions between working fluids and electrical fields. It is a facile, efficient, economical, and flexible route to prepare nanoscale fibers via a "top-down" approach. Four key components are required to implement this process as shown in Figure 1: (1) a high $(\mathrm{kV})$ voltage generator [18]; (2) an infusion pump, which can dispense solutions or melts at a precisely controlled rate; (3) a metal needle or spinneret; (4) a collector.

In electrospinning, a working fluid dispensed through the spinneret is stretched into nanoscale fibers by applying the high voltage electrostatic field $\left(F_{\text {field }}\right)$. The process can be divided into three steps as shown in Figure 1. First, the working fluid is extruded by the pump, and gathers on the tip of the spinneret. The droplet that would form in the absence of an electric field owing to surface tension is deformed into a conical shape (the Taylor cone) when a voltage is applied. This process is governed by a balance of gravity

"Corresponding author.Email: 191370148@st.usst.edu.cn
$(G)$, electrostatic repulsion $\left(F_{\text {er }}\right)$, and surface tension $\left(F_{\text {st }}\right)$. Second, the jet would not be ejected with charges until the voltage exceeds a specific critical value, which means electrostatic repulsion exceeds surface tension, linear jet formed. Third, the linear jet could sustain a short time due to Rayleigh Taylor instability, and the interaction between charges along with jet and electrostatic field, therefore, whipping and swing as a consequence. Working fluid with charges in the electricity field will be elongated by electrostatic repulsion among like charges on the jet surface, Coulomb repulsion $\left(F_{\mathrm{cr}}\right)$ between layers, and gravity. Meanwhile, the solvent evaporates rapidly and cure into fibers in microscale or even nanoscale.

The development of electrospinning has taken place over a prolonged period of time, as shown in Figure 2. In the 16th century, William Gibert recorded and reported the phenomenon of electrostatic interactions with liquids. He found that when a moderate amount of charge exists on a liquid droplet's surface, it deforms into a cone and then tiny drops are ejected from the tip. The droplet disintegrates into a mist under a suitable high electricity field. In 1885, the critical amount of charge required for droplet deformation was calculated by Lord Rayleigh, who proposed the first explanation of the electrospinning process [19].

In 1902, John Cooley was granted the first patent relating to electrospinning [20]. Formhals Anton applied for another patent in 1934, and this has been commercialized [21]. In the 1960s, Geoffrey Taylor systematically investigated the process of electrospinning [22,23], but after this time the technique fell out of favor. It was not until the 1990s that the group of Reneker conducted experiments to electrospin over 20 different polymers, and as a result were able to fabricate fibers on the nanoscale [24]. With the increasing interest in nanotechnology which the world has witnessed in recent decades, since this time the, electrospinning technology has developed rapidly. 


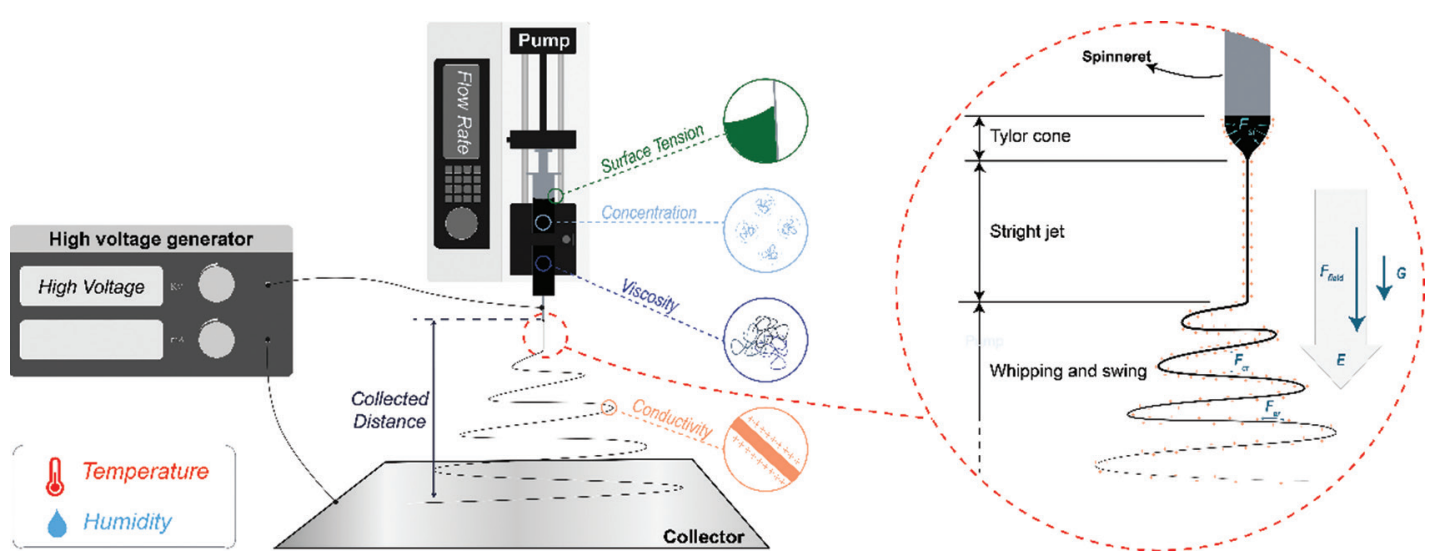

Figure $1 \mid$ Key parameters affecting the electrospinning process, and three stages within electrospinning with interactions.

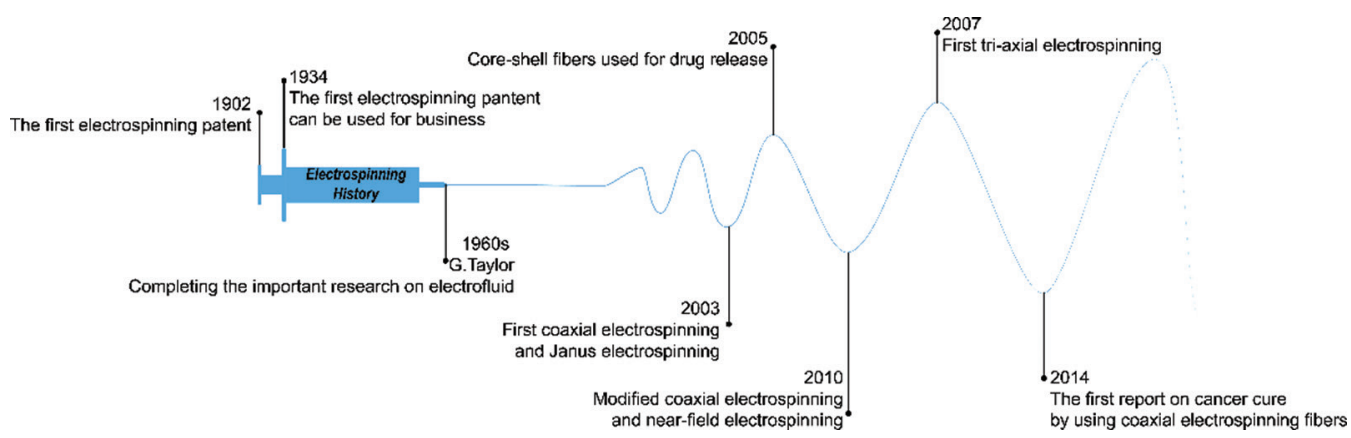

Figure 2 The development history of electrospinning.

Sun et al. [25] built on the standard single-fluid electrospinning process and developed core-shell fibers by processing two liquids in coaxial electrospinning in 2003. In the same year, Gupta and Wilkes [26] realized a side-by-side electrospinning approach which could also process two liquids. Building on this, Lallave et al. [27] performed triaxial electrospinning (with three fluids), and Yu et al. [28] developed new coaxial electrospinning processes permitting a wider range of fluids to be processed [28] and Zheng et al. [29] started work on near-field electrospinning. Three years later, a four fluids electrospinning process was reported [30]. In parallel to the development of the electrospinning technology, the applications of electrospinning have also advanced, such as for tissue scaffolds [31], drug delivery [1] or cancer treatment [32].

\section{MULTIFLUID ELECTROSPINNING PROCESSES}

Multifluid electrospinning has been explored for a number of years, and used to prepare a range of complex structures [33]. This can have a range of additional functionalities or improved performance compared to monolithic fibers from mono-axial spinning. To date, the most widely studied processes are coaxial, side-by-side (or Janus), and triaxial electrospinning.

\subsection{Coaxial Electrospinning}

The coaxial spinneret was one of the four spinnerets developed by Cooley in 1902, and the other three are traditional single fluid spinneret, the air-assist spinneret, and a spinneret with rotating the valve distributor [20]. Coaxial electrospinning (or electrospray) has been further development among 2002 and 2003. Moreover, modified coaxial electrospinning technology vastly expands the solution, which can be adopted in electrospinning.

Coaxial electrospinning provides the opportunity to develop diverse nanostructures (see Figure $3 a$ and $3 b$ ) with tunable functional performance. Coaxial electrospinning can be used to fabricate core-shell fibers (Figure 3a) [34,35], or hollow fibers (Figure 3b) [36-39]. Such core-shell structures can provide more functions. For example, heterojunction, which is a better way to transfer charge, can be formed between core and sheath [6,40,41]. For example, the sheath can be used to increase hydrophilicity, and the core to increase fiber strength. This has been found to produce materials which can be used for seawater desalination [42]. In addition, other properties of the core and sheath can also be implemented, such as concentration distribution [43], strength performance [44], or hydrophilic and hydrophobic properties [42].

Meantime, in modified coaxial electrospinning, first reported by Yu et al. [28], an unspinnable solution, which has too few chain entanglements to implement electrospinning process, could be used as the sheath solution. This could prevent the solvent rapidly evaporating (which is problematic because it might cause the fibers to have a rough surface). Furthermore, the working fluid can be more effectively well stretched in the electric field in the presence of a sheath solvent. As a result, the fibers produced tend to be finer. Using a modified coaxial electrospinning process with a pure solvent or dilute solution as the shell, problems which often arise with the formation of solid substances at the spinneret 


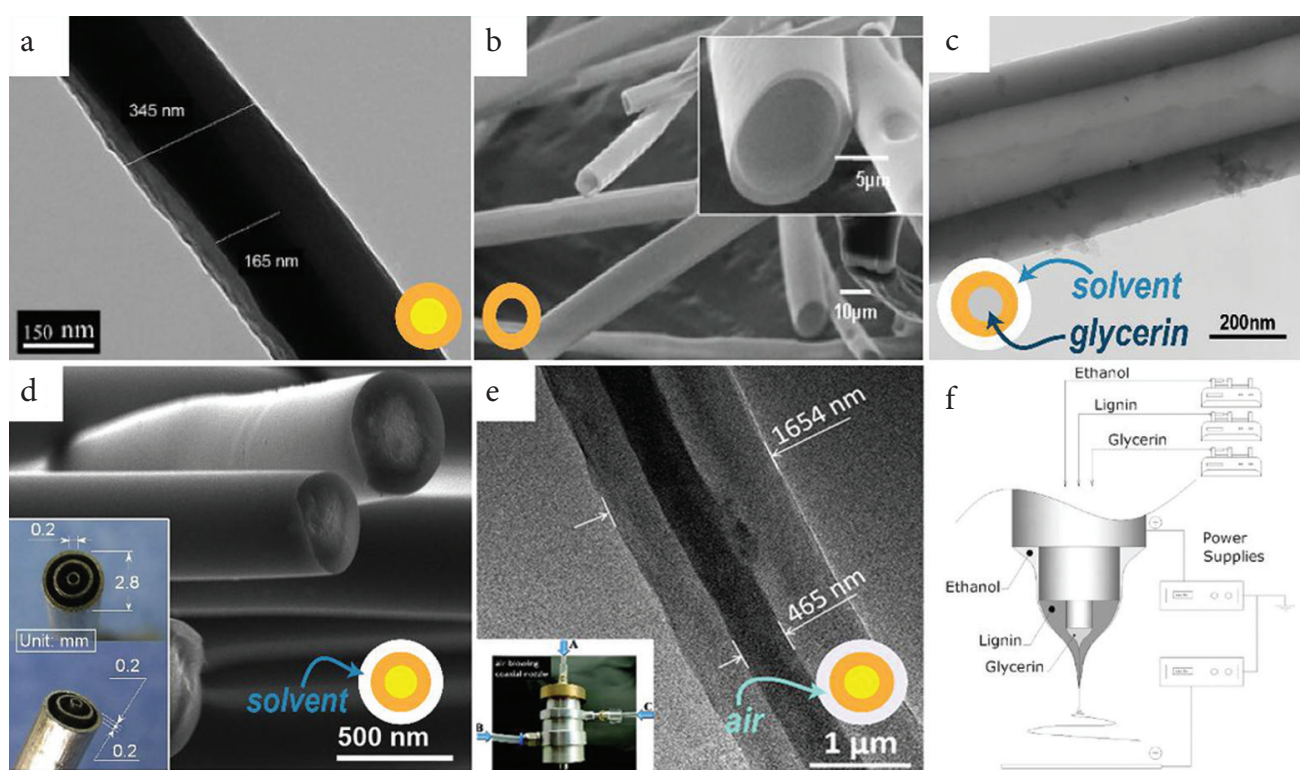

Figure 3 Core-shell and hollow fibers prepared by coaxial electrospinning. (a) Core-shell structure [Transmission Electron Microscopy (TEM) image]. (b) Hollow structure [Scanning Electron Microscopy (SEM) images]. Core-shell and hollow fibers prepared by tri-axial electrospinning. (c) single-wall hollow structure (TEM image). (d) Core-shell structure via modified tri-axial electrospinning (SEM image and the spinneret as inset) [45]. (e) Core-shell structure via air-blowing-assisted coaxial electrospinning [TEM image and picture for blow-assisted set: (A) inner capillary, (B) middle capillary, (C) outer bracket for air blow]. (f) It is the general set-up of (c) with different solutions in each layer.
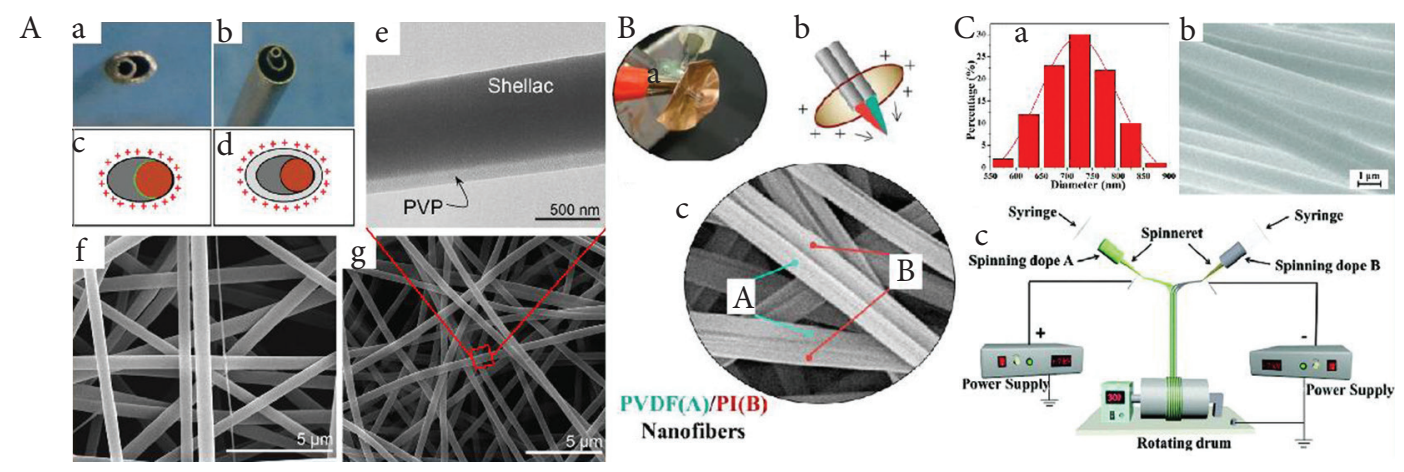

Figure 4 The influence of the spinneret on the structure of electrospun fibers. (A) Janus electrospinning: (a and b) pictures of the acentric and structured spinnerets; ( $c$ and d) schematics of the charged distribution and fluid contact interfaces; (e) Janus structures from structured spinneret F(TEM image); (f and g) fibers from acentric and structured spinnerets (SEM image) - Published by The Royal Society of Chemistry. (B) Side-by-side electrospinning: ( $a$ and b) picture and schematic of the specific spinnerets; (c) Janus structure nanofibers (SEM image). (C) Conjugate electrospinning: (a) diameter distribution of nanofibers in Janus Nanofiber Array Pellicle (JNAP); (b) SEM images of JNAP; (c) schematic diagram of the conjugate electrospinning Published by The Royal Society of Chemistry.

(and cause it to become blocked) and continuous electrospinning can be achieved $[46,47]$.

\subsection{Janus Electrospinning}

The Janus structure was first achieved using electrospinning by Gupta and Wilkes [26]. The Janus structure can be a better choice than uniaxial electrospinning in some cases, because two kinds of materials that provide different functions will affect each other. The separation will let them perform well $[48,49]$. A fiber with two parts and can realize two or three functions those can be mutual independence, such as fluorescence and magnetic properties $[48,50,51]$. Fluorescence property are easily affected by magnetic substances, which will lower the fluorescence property if the two materials mixed in one fiber. And they also can work together, such as light absorption and hydrophilicity [52], adsorption property and photocatalytic performance [6].

Two kinds of spinnerets have been used to fabricate Janus nanofibers. One comprises cylinders arranged side by side; the other one is a small cylinder touch a bigger cylinder internally as Figure 4A (a and c) $[53,54]$. With the former spinneret, it is very hard to prepare Janus nanofibers, because as a result of Coulombic repulsion there is a tendency of the fluids to repel one another and split apart [55]. As a result, researchers have developed more spinneret designs such as that shown in Figure $4 \mathrm{~B}(\mathrm{a}-\mathrm{c})$ [56]. Moreover, the latter spinneret enlarges the contact area between the two working fluids, which means the viscous force is increased. Janus fibers can also 
be prepared smoothly and continuedly if there is a shell solution around the two side-by-side fluids [Figure 4A(b and d)]. Compared with Figure $4 \mathrm{~A}(\mathrm{f})$ has few other finer fiber, Figure $4 \mathrm{~A}(\mathrm{~g})$ has a smoother morphology and clear Janus structure. Conjugate electrospinning process [Figure $4 \mathrm{C}(\mathrm{c})$ ] can also prepare Janus nanofibers with good size contribution [Figure $4 \mathrm{C}(\mathrm{b})$ ] and use a different method. Coulomb attraction plays a vital role in binding two fibers together, and then Janus fiber formed. For now, three forces can be used to conduct Janus electrospinning. They are Coulomb repulsion, Coulomb attraction, and viscous force, respectively. There may be other forces that could be used in electrospinning. And the combination of conjugate electrospinning and complex structure spinnerets could produce many possibilities.

\subsection{Triaxial Electrospinning}

Triaxial electrospinning uses three cylinders nested concentrically as the spinneret, which can be used for the electrospraying process as well, which uses unspinnable solutions to produce nanoparticles through same technalogy [57-59]. Here control of the operational parameters is particularly complicated because of the interaction between working fluids. Recently, triaxial electrospinning has begun to attract increasing attention; the recent reported on triaxial fibers are summarized in Table 1. Typical triaxial fibers are shown in Figure 5a.

Triaxial electrospinning can also be used to prepare core-shell and hollow structures. Using a pure solvent as the outer layer can protect the inner fluids preventing the solvent evaporating too fast and siding the formation the smooth fibers (Figure 3d). Furthermore, air can also be used as the shell in triaxial electrospinning as a role to increase the productivity of fiber by enhancing flow rate (Figure 3e). Hollow fiber and multiwall hollow fiber prepared by triaxial electrospinning have also been reported as Figure ( $3 \mathrm{c}$ and $3 \mathrm{f}$ ) and Zanjani et al. [4].

The utilize of mediate layer in triaxial fibers has been explored for many purposes. For example, the middle layer can be utilized as a restricted zone to realize molecule self-assemble into ultrafine nanoparticles [60]; a "nanowire in nanotube" structure can be prepared by removing the middle layer [61], and the middle layer can also act as a reinforcing phase for enhanced mechanical properties [62]. With further treatment including removal, carbonization, and modified, various morphology and structure will be obtained. For instance, Lee et al. combined triaxial electrospinning with carbonization to prepare a C-Si-C tri-layer nanofiber formulation, depicted in shown as Figure $5 c$. This has a very high specific capacity at a high current rate and potential in lithium-ion batteries [63]. Chen et al. [64] remove the mineral oil core of the core-shell fiber and decorated the resultant hollow fiber with nanoparticles (as Figure 5d), which gain led to used for good performance in Li-ion batteries.

The further development of multifluid electrospinning lies in two aspects. One is the creation of complex nanofibers on a large scale. Different from monoaxial electrospinning, very limited researches have been reported on the scale-up production of complex structural nanofibers using multifluid electrospinning, although the scaling up of monoaxial electrospinning has been reported for many years, particularly the needleless electrospinning, which is low-cost and high-efficient [81]. The other aspect is the reasonable design of multi-chamber spinnerets for implementing the corresponding multifluid electrospinning processes. This is not an easy thing because of the mutual influences of multiple factors. With the double-chamber side-by-side spinneret as an example, the repulsion of two working fluids with the same charges, their contact surface area at the co-exit, and their flow rates will co-exist on the behaviors of working fluids under the electrical fields, and in turn the integrity of the final Janus fibers.

\subsection{Other Multifluid Electrospinning Processes}

Core-shell and Janus structures have been most widely researched in multifluid electrospinning. However, other multifluid electrospinning can also be used to develop more complex, for example, multichannel nanofibers were prepared by two to five working fluids packaged through sheath solution $[82,83]$; high-quality Janus fiber was fabricated by surrounding solvent by using a complex structure spinneret shown as Figure $4 \mathrm{~A}$ (b and d) [55].

A four-layer fiber material has been prepared from a four-needle multiaxial electrospinning process. Labbaf et al. use Polyethylene Glycol (PEG), Poly(lactic-co-glycolic Acid) (PLGA), polycaprolactone (PCL) and polymethylsilsesquioxane as the outermost layer, second outermost layer, second innermost layer and innermost layer, respectively [30]. It is clear that the more layers bring more possible complex structures just like coaxial electrospinning and triaxial electrospinning.

\section{BIO-APPLICATIONS}

Owing to its advantages in developing nanofibers through a "onestep" process, the technology has been applied in various biological fields including drug release, tissue engineering, biosensor, wound dressing, theranostics and functional textile. Some of the functions which have been realized using electrospun fibers are depicted schematically in Figure 6.

\subsection{Tissue Engineering}

\subsubsection{Cell scaffolds}

Scaffolds play a crucial part in tissue engineering, aiding cell adhesion, growth, and proliferation. Effective scaffolds in tissue engineering: (1) be biocompatible and allow cells to adhere to them for growth; (2) have appropriate mechanical strength; (3) mimic the native extracellular matrix; (4) provide appropriate functionality at the implantation site; (5) possible sufficient durability.

Hydroxyapatite (HA) is extensively used in preparing bone tissue scaffolds. By using a mixture of hydroxyapatite and Tussah Silk Fibroin (TSF) as a core solution and pure TSF as the shell solution, researchers have used multifluid electrospinning to prepare scaffolds for use in bone tissue engineering. Compared with pure TSF scaffolds, the core-shell structure improves both strength of extension, and biocompatibility of scaffold [84]. 


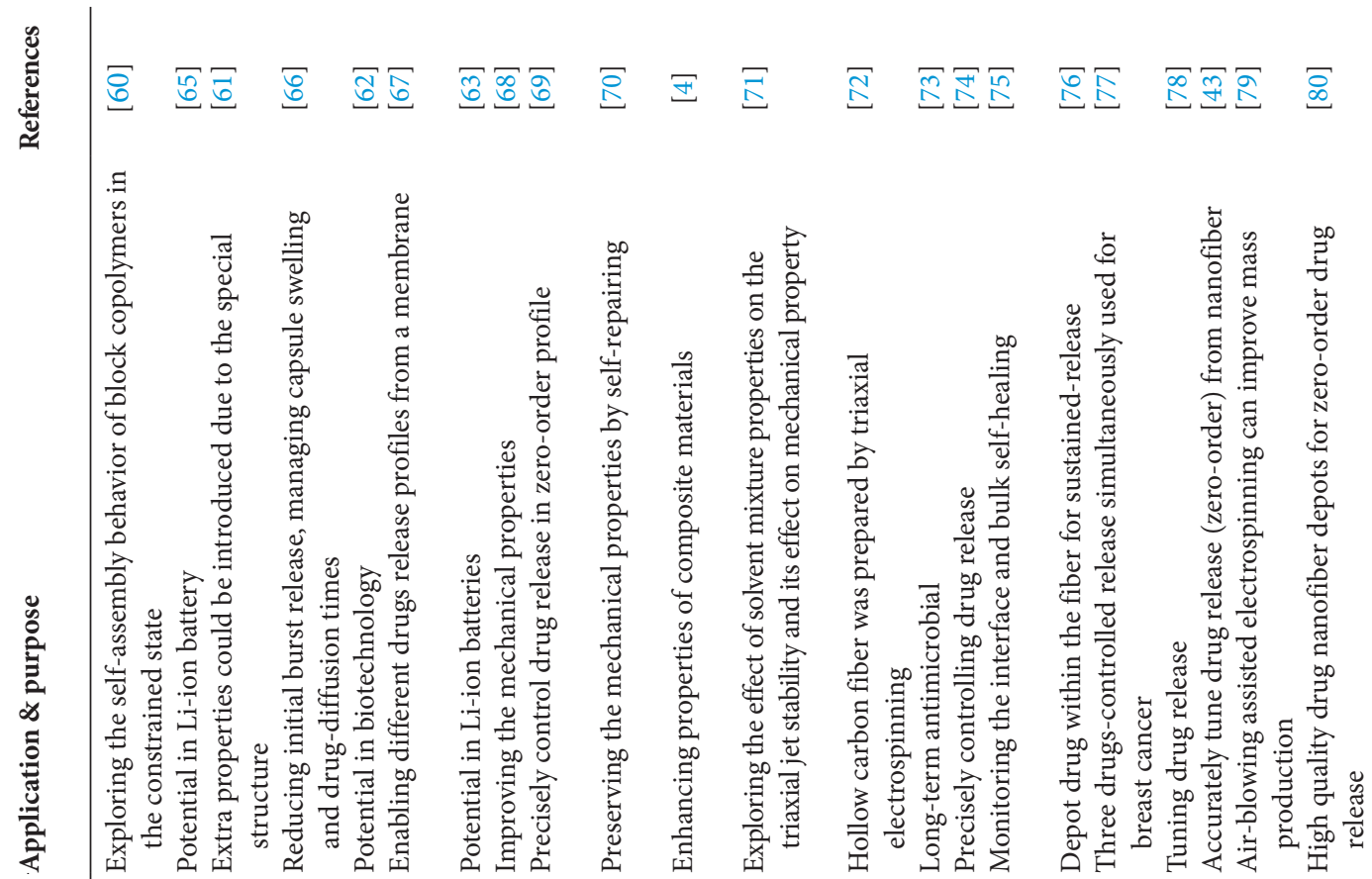

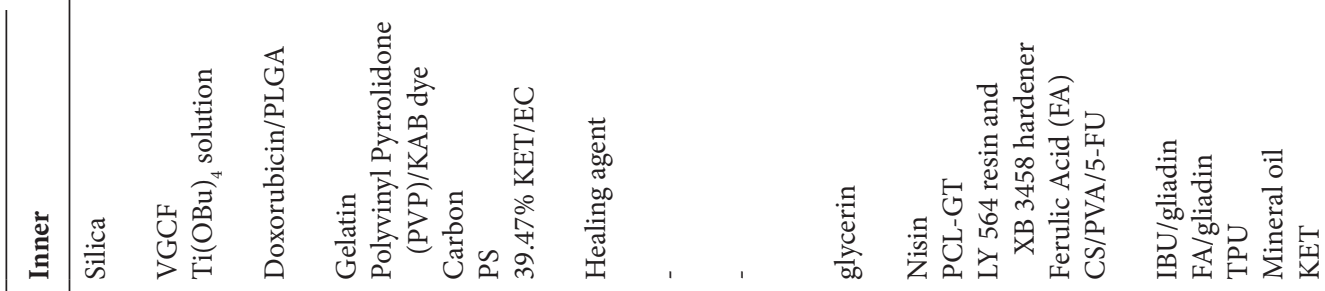

हี

है

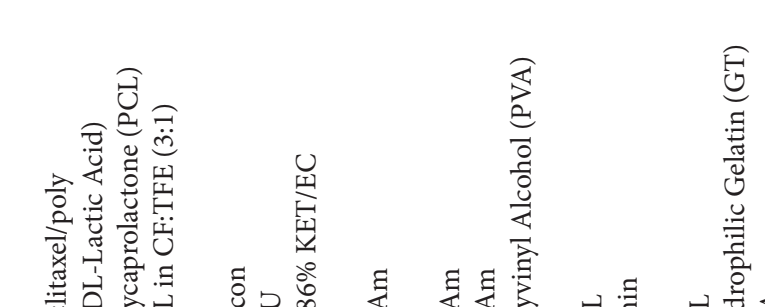

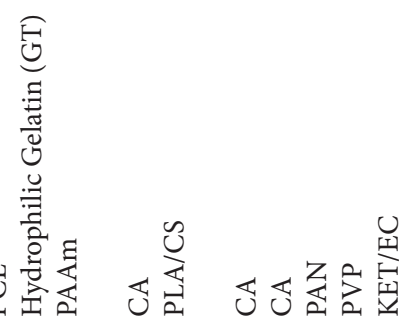

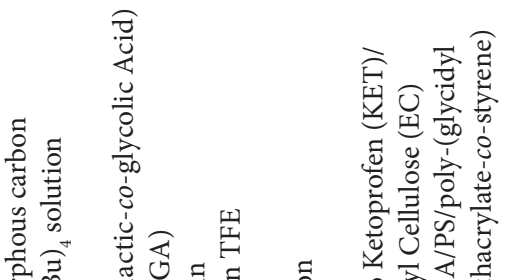



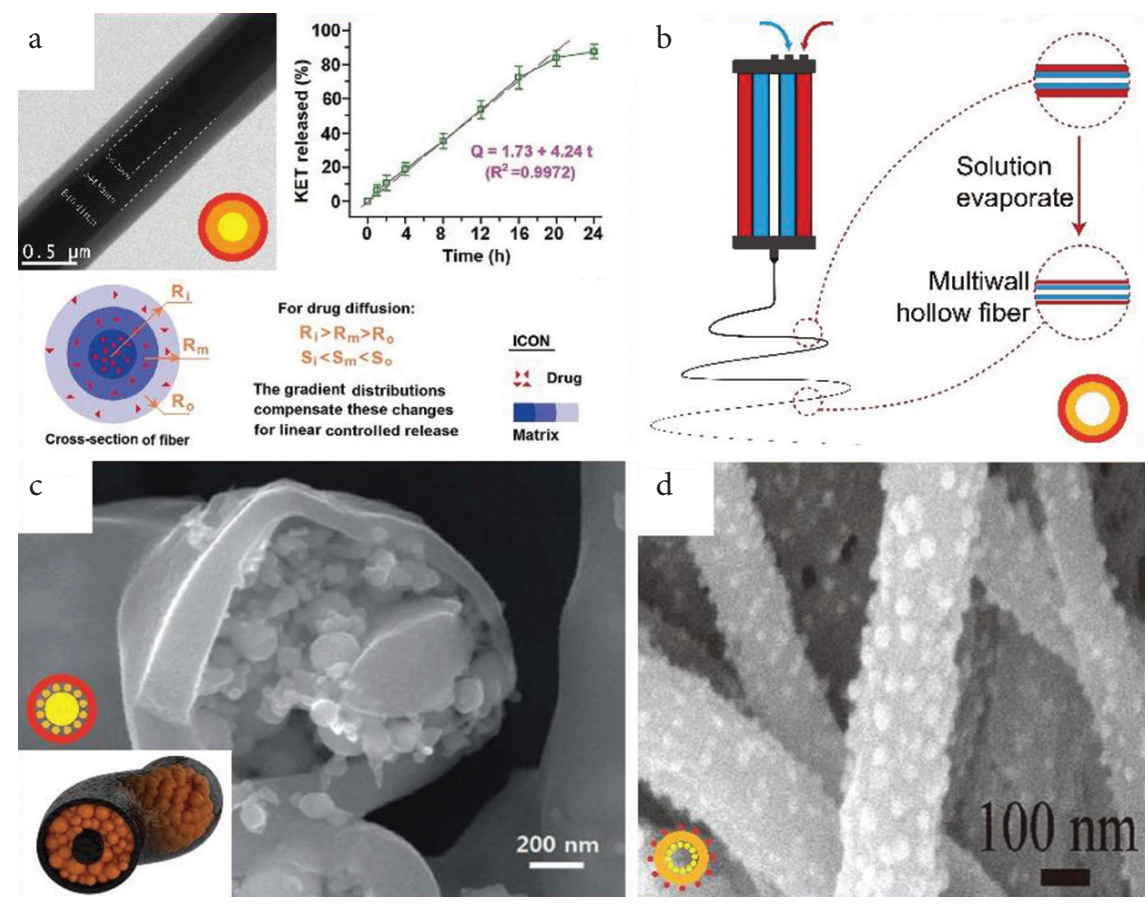

Figure 5 Selected three-layer structures prepared by triaxial electrospinning. (a) Triaxial nanofibers (TEM image) providing a linear drug release profile with a schematic explanation. (b) Diagram of preparing multiwall hollow structure fibers. (c) Tri-layer nanofiber with nanoparticles stored in medium layer (SEM image) and schematic diagram (inset). (d) Single-wall nanofiber decorated with nanoparticles inside and outside (SEM image).

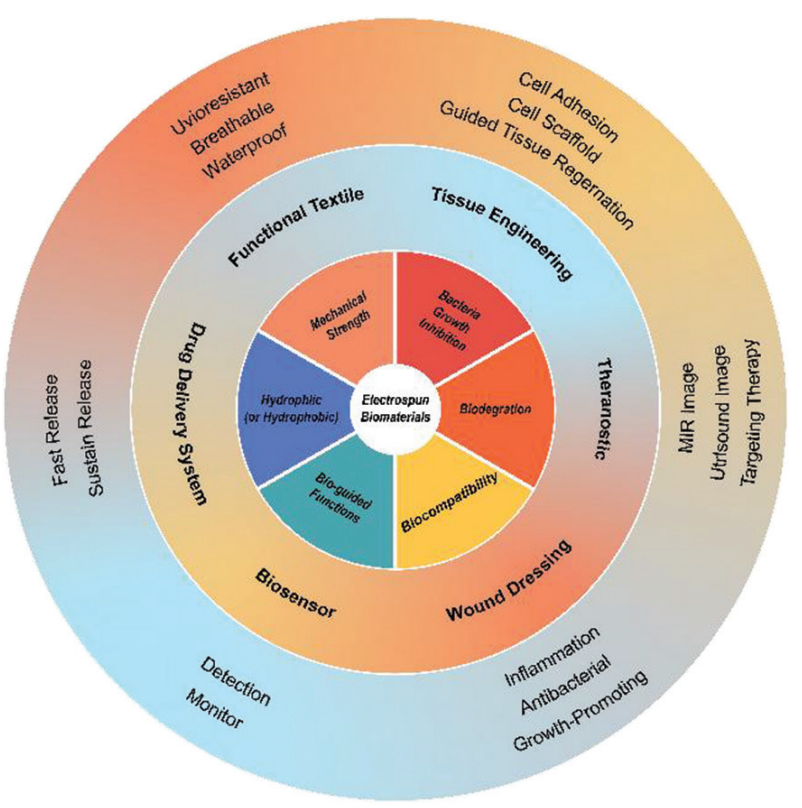

Figure 6 Schematic of the potential of electrospun nanofibers for use in biomedicine.

Multifluid electrospinning processes have also been used to prepare effective vascular tissue scaffolds [86]. However, in uniaxial electrospinning process, there is a trade-off among different functions within one fiber. With using coaxial electrospinning, core-shell fibers are prepared with better mechanical property than other fibers shown in Figure 7. A tubular vascular tissue engineering scaffold comprising PCL/collagen core-shell nanofibers was prepared by using coaxial electrospinning and found to have good biocompatibility and cell

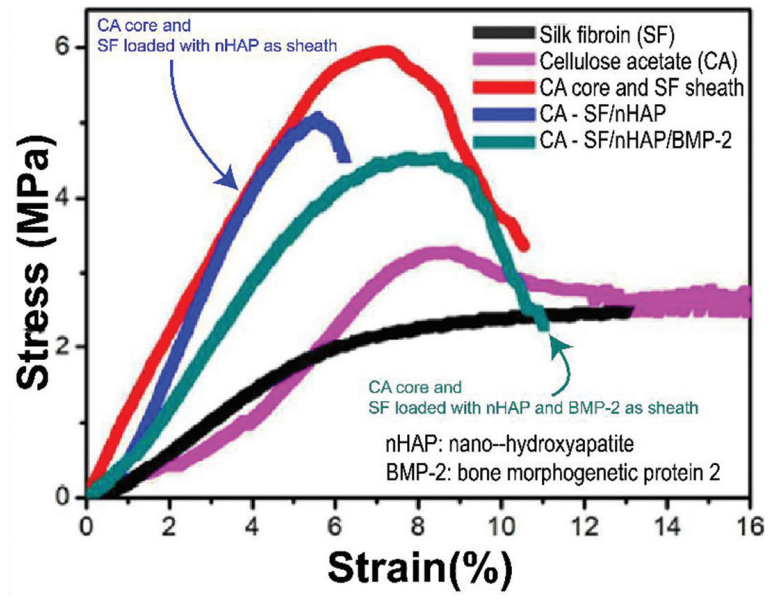

Figure 7 Multifluid electrospinning used for improving the mechanical strength and functions of core-shell fibers [85].

affinity [87]. Core-shell electrospun scaffolds with suitable mechanical properties, good hydrophilicity, the ability to promote osteoblast maturation and antibacterial properties were prepared by De-Paula et al. [88]. Coimbra et al. used PCL and synthetic gel-methacrylate (GelMA) in coaxial electrospinning to prepare a core-shell nanofiber network for vascular tissue regeneration. The content of gelatine influences the size distribution of the fibers and their hydrophilicity [89].

\subsubsection{Cell adhesion}

Since the expending of raw materials that can be used in electrospinning, various applications have been developed, such as 
peptide, protein [90], which benefit for developing the applications of electrospinning within biofield.

Biomaterials for cell adhesion must have the following properties: (1) Biocompatible materials, which allow cell can alive on and is safe to implant in the body or put on the skin, are necessary, such as gelatin, PCL, chitosan, Polylactic Acid (PLA) and so on [91-93]; (2) cell should has interaction with the biomaterial, which can improve the adhesion by incorporating specific materials, such as $\mathrm{ZnO}$ [94,95], peptides [96] (Arg-Gly-Asp [97], Arg-Glu-Asp-Val [98], CREDVW and CAGW [99]), protein [100] (silk fibroin [101], collagen [102]); (3) some cell adhesion biomaterials should possess the ability in improving cell proliferation and guiding their direction [103]. A highly anisotropic array film compose of Janus nanoribbons may provide a new strategy in guiding cell proliferation $[104,105]$.

With the using of multifluid electrospinning, various functional molecules can be incorporated into cell adhesion biomaterials. Shalumon et al. [106] prepared a kind of antibacterial core-shell nanofiber membrane which can be used for tendon adhesion with long-time anti-bacterial. Besides the selecting of various materials, some other reasons also affect cell adhesion, such as texture. Hughes-Brittain et al. [107] explored the influence of endothelial cell adhesion on the surface texture electrospun fibers, which means not only materials, but also texture on the fiber can also affect cell adhesion.

\subsubsection{Bio-regeneration}

Guided Tissue Regeneration (GTR) and Guided Bone Regeneration (GBR) membrane are two major present foci in bioregeneration. Multiple functions are needed to realize effective GTR and GBR membranes, such as drug release, durability, and guiding function. The traditional uniaxial electrospinning process can potentially might able to integrate multiple functions in a monolithic fiber with further treatments, but multifluid electrospinning can implement simpler in one-step. Tang et al. [108] used a coaxial process to produce a GTR membrane from PLGA and hydroxyapatite as the core and collagen and amoxicillin as the shell, and prepared core-shell fiber that performs well. Moreover, the effect of each function needs to be controlled. The initial burst release as a difficulty of the drug release process needs to be solved. In order to inhibit the production of bacteria on a scaffold, the drug release time needs to be extended [109]. We need the GTR to remain intact in the body for more than two months to ensure complete tissue repair [108]. Uniaxial electrospinning processes used to mix some substances into monolithic fiber. By using multifluid electrospinning processes, different layers perform their functions and work together.

Infection is a major for the failure of GBR membranes, and thus an extended period of drug release is required to prevent this and aid successful bone regeneration. Wang et al. [110] prepared electrospun PCL/gelatin core-shell nanofibers loaded with metronidazole in the core and nano-hydroxyapatite in the shell which prolonged the antibacterial efficacy and lowered the cytotoxicity of metronidazole. Xie et al. prepared core-shell fibers to control gene transfer to human periodontal ligament stem cells. This core-shell scaffold has an excellent gene release behavior and exhibited a prolonged-expression time [111].

\subsection{Drug Delivery System}

Along with the modern medicine booming, modern synthetic drugs are also present exponential growth, but most of the synthetic drug exists in the crystalline, poorly soluble in water that is substantially limited in application. Electrospinning appeared as a convenient, rapid prototyping technology, which can solidify working fluid in a very short period. It takes a uniform water-insoluble drug dissolve suitable solvent as the working fluid, which removes the solvent by rapid evaporation in the electric field, and fixes the drug to an amorphous state. In one recent study, Wang et al. used hydrophilic hydroxypropyl methylcellulose as the fiber-forming matrix polymer and an insoluble model drug Ferulic Acid (FA). Modified coaxial electrospinning was applied to produce nanofibers, which were found to release the embedded FA quickly. And X-ray diffraction result shows that FA was dispersed in nanofibers in an amorphous form [112].

However, in the process of drug release there typically an initial burst release and later tailing off when working with monolithic fibers from unaxial electrospinning. An appropriate burst release process will increase drug concentration to effective drug concentration in a short time, which requires precise control and constraint on drug release. Han and Steckl [67] observed the phenomenon of initial explosive release and later sustain release by using two dyes as release models through triaxial electrospinning. However, an initial burst if release can result in overly high drug concentrations which cause toxicity to the body; late trailing may lead to drug concentrations that are insufficient to produce the desired therapeutic effect. Wither initial burst can be control or not is important.

Using triaxial electrospinning technology, Yu et al. set different concentrations of Ketoprofen (KET) in the inner, middle, and outer working fluids, respectively. Furthermore, they took Ethyl Cellulose (EC) as the matrix to realize a zero-order drug release profile, with the release time exceeding $20 \mathrm{~h}$ as Figure 5a [69]. This team also used the same technology to encapsulate FA, an insoluble drug, in the CA, to achieve zero-order drug release over $36 \mathrm{~h}$ [76]. The use of the shell can also alleviate the initial burst [66]. Yang et al. [78] obtained the CA/ibuprofen-gliadin core-shell fiber by using modified triaxial electrospinning, which eliminated the initial burst and prolonged the drug release time. Later, this team explored the relationship between the thickness of CA shell and drug release through modified triaxial electrospinning [43].

In addition, it can often be desirable to deliver multiple drugs at the same time. One route to do this is to load multiple drugs in the same fiber formulation. Jouybari et al. [77] prepared three degradable three-layer fibers that can simultaneously control the release of three drugs through triaxial electrospinning, which can be used for treating breast cancer in vitro. Kim and Kim [66] prepared PLGA/ Poly(DL-Lactic Acid) (PDLLA) biodegradable triple-layered capsules for the release of taxol and doxorucin by triaxial electrospraying [66]. A more intuitive approach is to use side-by-side fibers to release two drugs. By using Polyvinyl Pyrrolidone (PVP) K60 and EC as substrates, Yu et al. [113] prepared parallel fibers that controlled the different release rate of KET.

\subsection{Wound Dressing}

Biocompatibility and antibacterial properties are key for effective wound dressings. Various antibacterial materials have been applied 
using electrospun nanofibers to generate wound dressing materials, such as Ag Nanoparticles (AgNPs) [114,115], honey [116], vitamin E [117], broad-spectrum antimicrobial (such as trimethoxysilylpropyl octadecyldimethyl ammonium chloride (QAS), ciprofloxacin, tetracycline hydrochloride and simvastatin) [118-120], peptides [121] and so on. However, the majority of studies have been undertaken using single-fluid electrospinning, which is problematic for fibers from single-fluid electrospinning cannot draw drug release profiles very well compared with multifluid electrospinning.

Multifluid Electrospinning could diminution wound dressing to nanoscale into fiber membranes and achieve good antibacterial properties and anti-inflammatory properties. Kalwar et al. [122] prepared a core-shell fiber membrane comprising PCL@chitosan nanofibers incorporating AgNPs, and found them to have good antibacterial properties. By using coaxial electrospinning, Heydari et al. [119] obtained an antibacterial and healing promotion coreshell membranes by loading simvastatin in the core and ciprofloxacin in the shell. Wen et al. [123] also prepared a dual-functional core-shell electrospun mat with the ability to accurately control the release of anti-inflammatory and anti-bacterial agents.

Nanofibers from multifluid electrospinning can also combine other functions, such as mechanical property, healing-promoting, biodegradable. Zahedi et al. [124] prepared core-shell fibers with a core containing Polyethylene Oxide (PEO)/Aloe vera extract and a shell comprising PCL/chitosan/keratin, which has great mechanical strength and can be used for wound healing. Wei et al. [125] use AgNPs and vitamin A palmitate as an antibacterial agent and healing-promoting drug in develop core-shell fibers. To overcome problems with wound healing in patients with type- 2 diabetes, Augustine et al. [126] used Connective Tissue Growth Factor (CTGF) in the preparation of membranes composed of nanofibers with a CTGF-Polyvinyl Alcohol (PVA) core and PLA shell, and these membranes were found to have excellent potential in cell proliferation, migration and angiogenesis. By utilizing the coaxial electrospinning process, Fang et al. prepared biodegradable nanofibers, which comprising poly $(\gamma$-glutamic acid $)$ as the core and PLA as the shell, with more than $90 \%$ re-epithelialization [127].

\subsection{Biosensor}

Electrospun fibers can be used in sensors for gas detection, such as ethanol [41], acetone [40], $\mathrm{H}_{2}$ [128], etc. However, when the sensor embedded in the body, it is a different environment and different substances needed to detect, such as dopamine [129], aflatoxin B1 [130], glucose [131,132], 25-hydroxy vitamin-D3 [133], urea [134], etc.

To improving sensitive and selective sensors, many tools have been incorporated in or loaded on electrospun fibers and used to detect singles, such as metal catalysts [129], inorganic compounds $[131,135]$, enzymes [136,137], antibodies [130], etc. Because of the very large specific surface area of electrospun nanofibers, electrospun biosensors have been found to be much more sensitive electrochemical than conventional sensors. Using multi-fluid electrospinning processes, hollow porous nanofibers can be prepared (see Figure 8a-8c) to construct heterogeneous junctions between the shell and the nanoparticle formed on shell porous. shown as Figure $8 \mathrm{e}$, which is conducive to the transformation of gas signals and electrical signals. From Figure 8d, it is clear that Pd-porous $\mathrm{WO}_{3}$ Nanotubes (NTs) performs better than porous $\mathrm{WO}_{3}$ NTs [128].

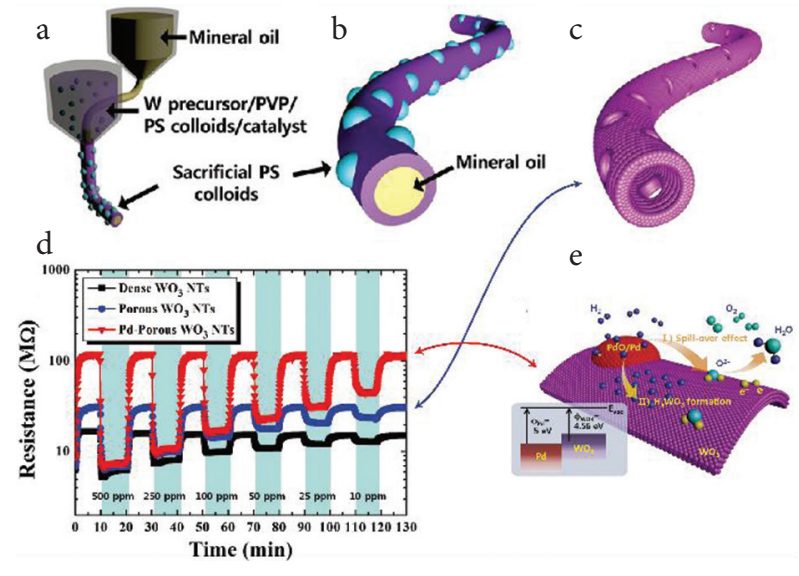

Figure 8 Core-shell nanofibers used for constructing heterojunction as a sensor. (a-c) $\mathrm{WO}_{3}$ NTs with multiple pores was prepared by coaxial electrospinning. (d) Dynamic resistance changes in detecting $\mathrm{H}_{2}$ using different materials: dense $\mathrm{WO}_{3} \mathrm{NTs}$, porous $\mathrm{WO}_{3} \mathrm{NTs}$, and Pd-porous $\mathrm{WO}_{3}$ NTs. (e) A schematic diagram of $\mathrm{H}_{2}$ sensing using Pd-porous $\mathrm{WO}_{3} \mathrm{NTs}$.

There are also reports of biosensor from coaxial electrospinning being used in vivo. Wang et al. prepared an implantable biosensor incorporating Pt-Glucose Oxidase (GOD) in order to detect glucose. The biosensor coated with core-shell fiber membranes, which compose $6 \mathrm{wt} \%$ polyurethane in core and $10 \mathrm{wt} \%$ gelatin in the shell, was immersed in phosphate buffer for 12 weeks also remain fiber morphology [138]. Furthermore, compared with core-shell heterogeneous [139], the Janus fibers can be used to construct heterogeneous junctions as well and load different tools to detect different substances. By utilizing heterogeneous junctions that play an important role in many fields [140], multifluid electrospinning processes can involve other fields easily.

\subsection{Theranostics}

Theranostics, which can diagnose and treat simultaneously, comprising an emerging field in biotechnology. It is one area where multifluid electrospinning could have great potential, because of its inherent ability to introduce multiple functions into nanomaterials. Signals, which can be detected by advanced technology or eyes or feelings, are essential characteristics that theranostic biomaterials should possess.

By using coaxial electrospinning, Jin et al. prepared core-shell nanofibers containing gadolinium (III) Diethylenetriaminepentaacetate [Gd(DTPA)] hydrate Gd(DTPA) as a contrast agent core and Eudragit S100 as a shell to allow the targeting of drug release. This core-shell nanofiber can be used for magnetic resonance imaging of the colon ex vivo [141]. This team also research on the simultaneous imaging and sustained drug release over $12-29 \mathrm{~h}$ at $\mathrm{pH} 7.4$ by using core-shell nanofibers [142].

\subsection{Functional Textiles}

Functional textiles based on electrospun nanofibers possess great potential. Many functions can be incorporated into membranes through single fluid electrospinning, such as waterproofing [143], 
antibacterial [144] and conductive [145] properties. Bin et al. have reported many studies on electrospun functional textiles for water-transport [146], ultraviolet resistance, waterproofing [147], waterproof-breathable [148], and air filters used for protect from $\mathrm{PM}_{2.5}$ [149].

We believe that multifluid electrospinning can perform better than monoaxial electrospinning in preparing multifunctional textiles, and is likely to lead to nanofiber membranes with more functions and better performance. Even so, problems remain to be overcome, such as scaleup. Scaling up monoaxial electrospinning has been explored for many years, and various solutions have been proposed [81]. However, relatively few reports discuss coaxial electrospinning scale-up [150], because of the difficulty of handling multiple fluids and ensuring that the desired multi-compartment products are generated.

\section{CONCLUSION AND PROSPECTS}

As a facile, low-cost, and flexible method to produce nanofibers, electrospinning has been explored in various bio-fields and the products have been found to have very good performance in many cases. We summarize here a range of different multifluid electrospinning processes, discussing some of the key parameters which must be considered in implementing an effective and reproducible process. Biomaterials composed of nanofibers prepared by multifluid electrospinning have been introduced, and selected studies highlighted to show the enhanced properties which can be achieved compared to the monolithic fibers from single-fluid spinning. Multifluid electrospinning processes can produce materials with many functions and structures that cannot be realized when working with a single solution. Challenges, such as the difficulty in scaling up multifluid electrospinning and structural spinnerets, have also been introduced. It is clear from the limited publications about multifluid electrospinning that the electrospun complicated nanostructures always showed a better functional performance than the corresponding monolithic nanofibers [151]. The reasons are obvious that multiple-chamber nanostructures are able to provide more opportunities for tailoring the components, compositions, and ingredient spatial distributions within the nanofibers, and thus act as a more powerful platform than the traditional blending electrospinning for endowing the electrospun nano products the desired functional performances $[152,153]$. In the authors' view multifluid electrospinning is likely to attract increasing attention owing to the exceptional performance that can be realized.

\section{CONFLICTS OF INTEREST}

The authors declare they have no conflicts of interest.

\section{REFERENCES}

[1] Jiang H, Hu Y, Li Y, Zhao P, Zhu K, Chen W. A facile technique to prepare biodegradable coaxial electrospun nanofibers for controlled release of bioactive agents. J Control Release 2005; 108:237-43.

[2] Zhan S, Zhu D, Ren G, Shen Z, Qiu M, Yang S, et al. Coaxialelectrospun magnetic core-shell Fe@TiSi nanofibers for the rapid purification of typical dye wastewater. ACS Appl Mater Interfaces 2014;6:16841-50.
[3] Wang M, Wang K, Yang Y, Liu Y, Yu DG. Electrospun environment remediation nanofibers using unspinnable liquids as the sheath fluids: a review. Polymers (Basel) 2020;12:103.

[4] Zanjani JSM, Saner Okan B, Menceloglu YZ, Yildiz M. Design and fabrication of multi-walled hollow nanofibers by triaxial electrospinning as reinforcing agents in nanocomposites. J Reinf Plast Compos 2015;34:1273-86.

[5] Jayasinghe SN. Cell electrospinning: a novel tool for functionalising fibres, scaffolds and membranes with living cells and other advanced materials for regenerative biology and medicine. Analyst 2013;138:2215-23.

[6] Zhou X, Shao C, Yang S, Li X, Guo X, Wang X, et al. Heterojunction of $g$-C3N4/biOI immobilized on flexible electrospun polyacrylonitrile nanofibers: facile preparation and enhanced visible photocatalytic activity for floating photocatalysis. ACS Sustain Chem Eng 2018;6:2316-23.

[7] Zhang J, Choi SW, Kim SS. Micro- and nano-scale hollow $\mathrm{TiO}_{2}$ fibers by coaxial electrospinning: Preparation and gas sensing. J Solid State Chem 2011;184:3008-13.

[8] Li Y, Zhou B, Zheng G, Liu X, Li T, Yan C, et al. Continuously prepared highly conductive and stretchable SWNT/MWNT synergistically composited electrospun thermoplastic polyurethane yarns for wearable sensing. J Mater Chem C 2018;6:2258-69.

[9] An AK, Guo J, Lee EJ, Jeong S, Zhao Y, Wang Z, et al. PDMS/ PVDF hybrid electrospun membrane with superhydrophobic property and drop impact dynamics for dyeing wastewater treatment using membrane distillation. J Membr Sci 2017;525:57-67.

[10] Li Y, Yin X, Yu J, Ding B. Electrospun nanofibers for highperformance air filtration. Compos Commun 2019;15:6-19.

[11] Lu P, Liang S, Qiu L, Gao Y, Wang Q. Thin film nanocomposite forward osmosis membranes based on layered double hydroxide nanoparticles blended substrates. J Membr Sci 2016;504:196-205.

[12] Lu P, Liang S, Zhou T, Xue T, Mei X, Wang Q. Layered double hydroxide nanoparticle modified forward osmosis membranes via polydopamine immobilization with significantly enhanced chlorine and fouling resistance. Desalination 2017;421:99-109.

[13] Zhang X, Zhao S, Fan W, Wang J, Li C. Long cycling, thermal stable, dendrites free gel polymer electrolyte for flexible lithium metal batteries. Electrochim Acta 2019;301:304-11.

[14] Wang K, Wen HF, Yu DG, Yang Y, Zhang DF. Electrosprayed hydrophilic nanocomposites coated with shellac for colonspecific delayed drug delivery. Mater Des 2018;143:248-55.

[15] Liu ZP, Zhang LL, Yang YY, Wu D, Jiang G, Yu DG. Preparing composite nanoparticles for immediate drug release by modifying electrohydrodynamic interfaces during electrospraying. Powder Technol 2018;327:179-87.

[16] Zhang C, Chang MW, Li Y, Qi Y, Wu J, Ahmad Z, Li JS. Janus particle synthesis via aligned non-concentric angular nozzles and electrohydrodynamic co-flow for tunable drug release. RSC Adv 2016;6:77174-8

[17] Gao Y, Zhao D, Chang MW, Ahmad Z, Li X, Suo H, et al. Morphology control of electrosprayed core-shell particles via collection media variation. Mater Lett 2015;146:59-64.

[18] Li C, Yin Y, Wang B, Zhou T, Wang J, Luo J, et al. Self-powered electrospinning system driven by a triboelectric nanogenerator. ACS Nano 2017;11:10439-45.

[19] Tucker N, Stanger JJ, Staiger MP, Razzaq H, Hofman K. The history of the science and technology of electrospinning from 1600 to 1995. J Eng Fibers \& Fabrics 2012;7:63-73.

[20] Cooley JF. Apparatus for electrically dispersing fluids, Google Patents, 1902. 
[21] Formhals A. Process and apparatus for preparing artificial threads, U.S. patent 1975504, 1934.

[22] Taylor GI. Disintegration of water drops in an electric field. Proc R Soc Lond Ser A Math Phys Sci 1964;280:383-97.

[23] Melcher JR, Taylor GI. Electrically driven jets. Proc R Soc Lond Ser A Math Phys Sci 1969;313:453-75.

[24] Reneker DH, Chun I. Nanometre diameter fibres of polymer, produced by electrospinning. Nanotechnology 1996;7:216.

[25] Sun Z, Zussman E, Yarin AL, WendorffJH, Greiner A. Compound core-shell polymer nanofibers by co-electrospinning. Adv Mater 2003;15:1929-32.

[26] Gupta P, Wilkes GL. Some investigations on the fiber formation by utilizing a side-by-side bicomponent electrospinning approach. Polymer 2003;44:6353-9.

[27] Lallave M, Bedia J, Ruiz-Rosas R, Rodríguez-Mirasol J, Cordero T, Otero JC, et al. Filled and hollow carbon nanofibers by coaxial electrospinning of alcell lignin without binder polymers. Adv Mater 2007;19:4292-6.

[28] Yu DG, Branford-White CJ, Chatterton NP, White K, Zhu LM, Shen XX, et al. Electrospinning of concentrated polymer solutions. Macromolecules 2010;43:10743-6.

[29] Zheng G, Li, W, Wang X, Wu D, Sun D, Lin L. Precision deposition of a nanofibre by near-field electrospinning. J Phys D Appl Phys 2010;43:415501.

[30] Labbaf S, Ghanbar H, Stride E, Edirisinghe M. Preparation of multilayered polymeric structures using a novel four-needle coaxial electrohydrodynamic device. Macromol Rapid Commun 2014;35:618-23.

[31] Zhang YZ, Venugopal J, Huang ZM, Lim CT, Ramakrishna S. Characterization of the surface biocompatibility of the electrospun pcl-collagen nanofibers using fibroblasts. Biomacromolecules 2005;6:2583-9.

[32] Yan E, Fan Y, Sun Z, Gao J, Hao X, Pei S, et al. Biocompatible coreshell electrospun nanofibers as potential application for chemotherapy against ovary cancer. Mater Sci Eng C 2014;41:217-23.

[33] Yu DG, Wang M, Li X, Liu X, Zhu LM, Annie Bligh SW. Multifluid electrospinning for the generation of complex nanostructures. Wiley Interdiscip Rev Nanomed Nanobiotechnol 2020;12:e1601.

[34] Zhu J, Huang W, Zhang Q, Ling S, Chen Y, Kaplan DL. Aqueousbased coaxial electrospinning of genetically engineered silk elastin core-shell nanofibers. Materials 2016;9:221.

[35] Zhu LF, Zheng Y, Fan J, Yao Y, Ahmad Z, Chang MW. A novel core-shell nanofiber drug delivery system intended for the synergistic treatment of melanoma. Eur J Pharm Sci 2019;137:105002.

[36] Wang B, Zheng H, Chang MW, Ahmad Z, Li JS. Hollow polycaprolactone composite fibers for controlled magnetic responsive antifungal drug release. Colloids Surf B Biointerfaces 2016;145:757-67.

[37] Dror Y, Salalha W, Avrahami R, Zussman E, Yarin AL, Dersch R, et al. One-step production of polymeric microtubes by coelectrospinning. Small 2007;3:1064-73.

[38] Zhang C, Ding Q, He H, Peng Y, Li C, Mai J, et al. Nanoporous hollow fibers as a phantom material for the validation of diffusion magnetic resonance imaging. J Appl Polym Sci 2019;136:47617.

[39] Wu S, Wang B, Ahmad Z, Huang J, Chang MW, Li JS. Surface modified electrospun porous magnetic hollow fibers using secondary downstream collection solvent contouring. Mater Lett 2017;204:73-6.
[40] Li F, Zhang T, Gao X, Wang R, Li B. Coaxial electrospinning heterojunction $\mathrm{Sno}_{2} / \mathrm{Au}$-doped $\mathrm{In}_{2} \mathrm{O}_{3}$ core-shell nanofibers for acetone gas sensor. Sens Actuat B Chem 2017;252:822-30.

[41] Huang B, Zhang Z, Zhao C, Cairang L, Bai J, Zhang Y, et al. Enhanced gas-sensing performance of $\mathrm{ZnO} @ \mathrm{In}_{2} \mathrm{O}_{3}$ core@shell nanofibers prepared by coaxial electrospinning. Sens Actuat B Chem 2018;255:2248-57.

[42] Shibuya M, Park MJ, Lim S, Phuntsho S, Matsuyama H, Shon HK. Novel CA/PVDF nanofiber supports strategically designed via coaxial electrospinning for high performance thin-film composite forward osmosis membranes for desalination. Desalination 2018;445:63-74.

[43] Liu X, Yang Y, Yu DG, Zhu MJ, Zhao M, Williams GR. Tunable zero-order drug delivery systems created by modified triaxial electrospinning. Chem Eng J 2019;356:886-94.

[44] He P, Zhong Q, Ge Y, Guo Z, Tian J, Zhou Y, et al. Dual drug loaded coaxial electrospun plga/pvp fiber for guided tissue regeneration under control of infection. Mater Sci Eng C Mater Biol Appl 2018;90:549-56.

[45] Yang C, Yu DG, Pan D, Liu XK, Wang X, Bligh SA, Williams GR. Electrospun ph-sensitive core-shell polymer nanocomposites fabricated using a tri-axial process. Acta Biomater 2016;35:77-86.

[46] Wen HF, Yang C, Yu DG, Li XY, Zhang DF. Electrospun zein nanoribbons for treatment of lead-contained wastewater. Chem Eng J 2016;290:263-72.

[47] Yao ZC, Gao Y, Chang MW, Ahmad Z, Li JS. Regulating poly-caprolactone fiber characteristics in-situ during onestep coaxial electrospinning via enveloping liquids. Mater Lett 2016;183:202-6.

[48] Wang G, Ma Q, Tian J, Fan L, Li D, Dong X, et al. Janus nanofiber array pellicle: facile conjugate electrospinning construction, structure and bifunctionality of enhanced green fluorescence and adjustable magnetism. RSC Adv 2019;9:206-14.

[49] Lv N, Ma Q, Dong X, Wang J, Yu W, Liu G. Flexible janus nanofibers: facile electrospinning construction and enhanced luminescent-electrical-magnetic trifunctionality. ChemPlusChem 2014;79:690-7.

[50] Wang Q, Geng Y, Li J, Yin M, Hu Y, Liu Y, et al. Novel magnetic-fluorescent bifunctional janus nanofiber membrane. Nanotechnology 2018;29:135702.

[51] Tian J, Ma Q, Yu W, Li D, Dong X, Liu G, et al. Preparation of janus microfibers with magnetic and fluorescence functionality via conjugate electro-spinning. Mater Des 2019;170:107701.

[52] Xu W, Hu X, Zhuang S, Wang Y, Li X, Zhou L, et al. Flexible and salt resistant janus absorbers by electrospinning for stable and efficient solar desalination. Adv Energy Mater 2018;8:1702884.

[53] Li X, Deng L, Yu, X, Wang M, Wang X, García-Payo C, et al. A novel profiled core-shell nanofibrous membrane for wastewater treatment by direct contact membrane distillation. J Mater Chem A 2016;4:14453-63.

[54] Grojean RE, Sousa JA, Henry MC. Utilization of solar radiation by polar animals: an optical model for pelts. Appl. Opt 1980;19:339-46.

[55] Yu DG, Li JJ, Zhang M, Williams GR. High-quality janus nanofibers prepared using three-fluid electrospinning. Chem Commun (Camb) 2017;53:4542-5.

[56] Cai M, He H, Zhang X, Yan X, Li J, Chen F, et al. Efficient synthesis of PVDF/PI side-by-side bicomponent nanofiber membrane 
with enhanced mechanical strength and good thermal stability. Nanomaterials (Basel) 2019;9:39.

[57] Zhang C, Yao ZC, Ding Q, Choi JJ, Ahmad Z, Chang MW, et al. Tri-needle coaxial electrospray engineering of magnetic polymer yolk-shell particles possessing dual-imaging modality, multiagent compartments, and trigger release potential. ACS Appl Mater Interfaces 2017;9:21485-95.

[58] Zhang C, Li Y, Hu Y, Peng Y, Ahmad Z, Li JS, et al. Porous yolkshell particle engineering via nonsolvent-assisted trineedle coaxial electrospraying for burn-related wound healing. ACS Appl Mater Interfaces 2019;11:7823-35.

[59] Xing Z, Zhang C, Zhao C, Ahmad Z, Li JS, Chang MW. Targeting oxidative stress using tri-needle electrospray engineered ganoderma lucidum polysaccharide-loaded porous yolk-shell particles. Eur J Pharm Sci 2018;125:64-73.

[60] Kalra V, Lee JH, Park JH, Marquez M, Joo YL. Confined assembly of asymmetric block-copolymer nanofibers via multiaxial jet electrospinning. Small 2009;5:2323-32.

[61] Chen H, Wang N, Di J, Zhao Y, Song Y, Jiang L. Nanowire-inmicrotube structured core/shell fibers via multifluidic coaxial electrospinning. Langmuir 2010;26:11291-6.

[62] Liu W, Ni C, Chase DB, Rabolt JF. Preparation of multilayer biodegradable nanofibers by triaxial electrospinning. ACS Macro Lett 2013;2:466-8.

[63] Lee BS, Yang HS, Jung H, Jeon SY, Jung C, Kim SW, et al. Novel multi-layered 1-D nanostructure exhibiting the theoretical capacity of silicon for a super-enhanced lithium-ion battery. Nanoscale 2014;6:5989-98.

[64] Chen Y, Lu Z, Zhou L, Mai YW, Huang H. Triple-coaxial electrospun amorphous carbon nanotubes with hollow graphitic carbon nanospheres for high-performance Li ion batteries. Energy Environ Sci 2012;5:7898-902.

[65] Hosono E, Wang Y, Kida N, Enomoto M, Kojima N, Okubo M, et al. Synthesis of triaxial $\mathrm{LiFePO}_{4}$ nanowire with a VGCF core column and a carbon shell through the electrospinning method. ACS Appl Mater Interfaces 2010;2:212-18.

[66] Kim W, Kim SS. Synthesis of biodegradable triple-layered capsules using a triaxial electrospray method. Polymer 2011;52:3325-36.

[67] Han D, Steckl AJ. Triaxial electrospun nanofiber membranes for controlled dual release of functional molecules. ACS Appl Mater Interfaces 2013;5:8241-5.

[68] Jiang S, Duan G, Zussman E, Greiner A, Agarwal S. Highly flexible and tough concentric triaxial polystyrene fibers. ACS Appl Mater Interfaces 2014;6:5918-23.

[69] Yu DG, Li XY, Wang X, Yang JH, Bligh SA, Williams GR. Nanofibers fabricated using triaxial electrospinning as zero order drug delivery systems. ACS Appl Mater Interfaces 2015;7:18891-7.

[70] Zanjani JSM, Okan BS, Letofsky-Papst I, Menceloglu Y, Yildiz M. Repeated self-healing of nano and micro scale cracks in epoxy based composites by tri-axial electrospun fibers including different healing agents. RSC Adv 2015;5:73133-45.

[71] Khalf A, Singarapu K, Madihally SV. Influence of solvent characteristics in triaxial electrospun fiber formation. React Funct Polym 2015;90:36-46.

[72] Panzavolta S, Gualandi C, Fiorani A, Bracci B, Focarete ML, Bigi A. Fast coprecipitation of calcium phosphate nanoparticles inside gelatin nanofibers by tricoaxial electrospinning. J Nanomaterials 2016;2016:1-7.

[73] Han D, Sherman S, Filocamo S, Steckl AJ. Long-term antimicrobial effect of nisin released from electrospun triaxial fiber membranes. Acta Biomater 2017;53:242-9.
[74] Khalf A, Madihally SV. Modeling the permeability of multiaxial electrospun $\operatorname{poly}(\varepsilon$-caprolactone)-gelatin hybrid fibers for controlled doxycycline release. Mater Sci Eng C Mater Biol Appl 2017;76:161-70.

[75] Zanjani JSM, Okan BS, Yilmaz C, Menceloglu Y, Yildiz M. Monitoring the interface and bulk self-healing capability of tri-axial electrospun fibers in glass fiber reinforced epoxy composites. Compos A Appl Sci Manuf 2017;99:221-32.

[76] Yang GZ, Li JJ, Yu DG, He MF, Yang JH, Williams GR. Nanosized sustained-release drug depots fabricated using modified tri-axial electrospinning. Acta Biomater 2017;53:233-41.

[77] Jouybari MH, Hosseini S, Mahboobnia K, Boloursaz LA, Moradi M, Irani M. Simultaneous controlled release of 5-FU, DOX and PTX from chitosan/PLA/5-FU/g-C3N4-DOX/g-C3N4-PTX triaxial nanofibers for breast cancer treatment in vitro. Colloids Surf B Biointerfaces 2019;179:495-504.

[78] Yang Y, Li W, Yu DG, Wang G, Williams G.R, Zhang Z. Tunable drug release from nanofibers coated with blank cellulose acetate layers fabricated using tri-axial electrospinning. Carbohydr Polym 2019;203:228-37.

[79] Duan G, Greiner A. Air-blowing-assisted coaxial electrospinning toward high productivity of core/sheath and hollow fibers. Macromol Mater Eng 2019;304:1800669.

[80] Huang CK, Zhang K, Gong Q, Yu DG, Wang J, Tan X, et al. Ethylcellulose-based drug nano depots fabricated using a modified triaxial electrospinning. Int J Biol Macromol 2020;152:68-76.

[81] Yu M, Dong RH, Yan X, Yu GF, You MH, Ning X, et al. Recent advances in needleless electrospinning of ultrathin fibers: from academia to industrial production. Macromol Mater Eng 2017;302:1700002.

[82] Zhao Y, Cao X, Jiang L. Bio-mimic multichannel microtubes by a facile method. J Am Chem Soc 2007;129:764-5.

[83] Wang B, Wang M, Chang MW, Ahmad Z, Huang J, Li Js. Nonconcentric multi-compartment fibers fabricated using a modified nozzle in single-step electrospinning. Mater Lett 2017;202:134-7.

[84] Shao W, He J, Sang F, Ding B, Chen L, Cui S, et al. Coaxial electrospun aligned tussah silk fibroin nanostructured fiber scaffolds embedded with hydroxyapatite-tussah silk fibroin nanoparticles for bone tissue engineering. Mater Sci Eng C Mater Biol Appl 2016;58:342-51

[85] Tao C, Zhang Y, Li B, Chen L. Hierarchical micro/submicrometerscale structured scaffolds prepared via coaxial electrospinning for bone regeneration. J Mater Chem B 2017;5:9219-28.

[86] Vaz C, van Tuijl S, Bouten C, Baaijens F. Design of scaffolds for blood vessel tissue engineering using a multi-layering electrospinning technique. Acta Biomater 2005;1:575-82.

[87] Duan N, Geng X, Ye L, Zhang A, Feng Z, Guo L, et al. A vascular tissue engineering scaffold with core-shell structured nanofibers formed by coaxial electrospinning and its biocompatibility evaluation. Biomed Mater 2016;11:035007.

[88] De-Paula MMM, Afewerki S, Viana BC, Webster TJ, Lobo AO, Marciano FR. Dual effective core-shell electrospun scaffolds: promoting osteoblast maturation and reducing bacteria activity. Mater Sci Eng C Mater Biol Appl 2019;103:109778.

[89] Coimbra P, Santos P, Alves P, Miguel SP, Carvalho MP, de Sá KD, et al. Coaxial electrospun PCL/Gelatin-MA fibers as scaffolds for vascular tissue engineering. Colloids Surf B Biointerfaces 2017;159:7-15.

[90] Dart A, Bhave M, Kingshott P. Antimicrobial peptide-based electrospun fibers for wound healing applications. Macromol Biosci 2019;19:1800488. 
[91] Pereira FAS, Salles GN, Rodrigues BVM, Marciano FR, Pacheco-Soares C, Lobo AO. Diamond nanoparticles into poly (lactic acid) electrospun fibers: cytocompatible and bioactive scaffolds with enhanced wettability and cell adhesion. Mater Lett 2016;183:420-4.

[92] Kirbay FO, Yalcinkaya EE, Atik G, Evren G, Unal B, Demirkol DO, et al. Biofunctionalization of PAMAM-montmorillonite decorated poly ( $\varepsilon$-caprolactone)-chitosan electrospun nanofibers for cell adhesion and electrochemical cytosensing. Biosens Bioelectron 2018;109:286-94.

[93] Huang CY, Hu KH, Wei ZH. Comparison of cell behavior on pva/pva-gelatin electrospun nanofibers with random and aligned configuration. Sci Rep 2016;6:37960.

[94] Augustine R, Malik HN, Singhal DK, Mukherjee A, Malakar D, Kalarikkal N, et al. Electrospun polycaprolactone/ZnO nanocomposite membranes as biomaterials with antibacterial and cell adhesion properties. J Polym Res 2014;21:347.

[95] Augustine R, Dan P, Sosnik A, Kalarikkal N, Tran N, Vincent B, et al. Electrospun poly(vinylidene fluoride-trifluoroethylene)/ zinc oxide nanocomposite tissue engineering scaffolds with enhanced cell adhesion and blood vessel formation. Nano Res 2017;10:3358-76.

[96] Kaur G, Kumari S, Saha P, Ali R, Patil S, Ganesh S, et al. Selective cell adhesion on peptide-polymer electrospun fiber mats. ACS Omega 2019;4:4376-83.

[97] Kim TG, Park TG. Biomimicking extracellular matrix: cell adhesive RGD peptide modified electrospun poly(D,L-lacticco-glycolic acid) nanofiber mesh. Tissue Eng 2006;12:221-33.

[98] Zhou F, Jia X, Yang Y, Yang Q, Gao C, Zhao Y, et al. Peptidemodified pelcl electrospun membranes for regulation of vascular endothelial cells. Mater Sci Eng C Mater Biol Appl 2016;68:623-31.

[99] Bai L, Zhao J, Li Q, Guo J, Ren X, Xia S, et al. Biofunctionalized electrospun PCL-PIBMD/SF vascular grafts with PEG and cell-adhesive peptides for endothelialization. Macromol Biosci 2019;19:e1800386.

[100] Kim BJ, Cheong H, Choi ES, Yun SH, Choi BH, Park KS, et al. Accelerated skin wound healing using electrospun nanofibrous mats blended with mussel adhesive protein and polycaprolactone. J Biomed Mater Res A 2017;105:218-25.

[101] Min BM, Lee G, Kim SH, Nam YS, Lee TS, Park WH. Electrospinning of silk fibroin nanofibers and its effect on the adhesion and spreading of normal human keratinocytes and fibroblasts in vitro. Biomaterials 2004;25:1289-97.

[102] Schnell E, Klinkhammer K, Balzer S, Brook G, Klee D, Dalton P, et al. Guidance of glial cell migration and axonal growth on electrospun nanofibers of poly- $\varepsilon$-caprolactone and a collagen/ poly-e-caprolactone blend. Biomaterials 2007;28:3012-25.

[103] Ma Z, He W, Yong T, Ramakrishna S. Grafting of gelatin on electrospun poly(caprolactone) nanofibers to improve endothelial cell spreading and proliferation and to control cell orientation. Tissue Eng 2005;11:1149-58.

[104] Ma Q, Wang J, Dong X, Yu W, Liu G. Flexible janus nanoribbons array: a new strategy to achieve excellent electrically conductive anisotropy, magnetism, and photoluminescence. Adv Funct Mater 2015;25:2436-43.

[105] Xi X, Yu W, Li D, Ma Q, Dong X, Wang J, Liu G. Assembling exceptionally-structured janus nanoribbons into a highly anisotropic electrically conductive array film that exhibits red fluorescence and superparamagnetism. New J Chem 2018;42:18708-16.

[106] Shalumon KT, Sheu C, Chen CH, Chen SH, Jose G, Kuo CY, et al. Multi-functional electrospun antibacterial core-shell nanofibrous membranes for prolonged prevention of postsurgical tendon adhesion and inflammation. Acta Biomater 2018;72:121-36.

[107] Hughes-Brittain NF, Qiu L, Picot OT, Wang W, Peijs T, Bastiaansen CWM. Surface texturing of electrospun fibres by photoembossing using pulsed laser interference holography and its effects on endothelial cell adhesion. Polymer 2017;125:40-9.

[108] Tang Y, Chen L, Zhao K, Wu Z, Wang Y, Tan Q. Fabrication of PLGA/HA (core)-collagen/amoxicillin (shell) nanofiber membranes through coaxial electrospinning for guided tissue regeneration. Compos Sci Technol 2016;125:100-7.

[109] He M, Jiang H, Wang R, Xie Y, Zhao C. Fabrication of metronidazole loaded poly ( $\varepsilon$-caprolactone)/zein core/shell nanofiber membranes via coaxial electrospinning for guided tissue regeneration. J Colloid Interface Sci 2017;490:270-8.

[110] Wang Y, Jiang Y, Zhang Y, Wen S, Wang Y, Zhang H. Dual functional electrospun core-shell nanofibers for anti-infective guided bone regeneration membranes. Mater Sci Eng C 2019;98:134-9.

[111] Xie Q, Jia LN, Xu HY, Hu XG, Wang W, Jia J. Fabrication of core-shell PEI/pBMP2-PLGA electrospun scaffold for gene delivery to periodontal ligament stem cells. Stem Cells Int 2016;2016:5385137.

[112] Wang Q, Yu DG, Zhang LL, Liu XK, Deng YC, Zhao M. Electrospun hypromellose-based hydrophilic composites for rapid dissolution of poorly water-soluble drug. Carbohydr Polym 2017;174:617-25.

[113] Yu DG, Yang C, Jin M, Williams GR, Zou H, Wang X, et al. Medicated janus fibers fabricated using a teflon-coated side-byside spinneret. Colloids Surf B Biointerfaces 2016;138:110-6.

[114] Wang Y, Li P, Xiang P, Lu J, Yuan J, Shen J. Electrospun polyurethane/keratin/AgNP biocomposite mats for biocompatible and antibacterial wound dressings. J Mater Chem B 2016;4:635-48.

[115] Yang J, Wang K, Yu DG, Yang Y, Bligh SWA, Williams GR. Electrospun janus nanofibers loaded with a drug and inorganic nanoparticles as an effective antibacterial wound dressing. Mater Sci Eng C Mater Biol Appl 2020;111:110805.

[116] Yang X, Fan L, Ma L, Wang Y, Lin S, Yu F, et al. Green electrospun manuka honey/silk fibroin fibrous matrices as potential wound dressing. Mater Des 2017;119:76-84.

[117] Li H, Wang M, Williams GR, Wu J, Sun X, Lv Y, et al. Electrospun gelatin nanofibers loaded with vitamins $\mathrm{A}$ and $\mathrm{E}$ as antibacterial wound dressing materials. RSC Adv 2016;6:50267-77.

[118] Shi R, Geng H, Gong M, Ye J, Wu C, Hu X, et al. Long-acting and broad-spectrum antimicrobial electrospun poly ( $\varepsilon$-caprolactone)/gelatin micro/nanofibers for wound dressing. J Colloid Interface Sci 2018;509:275-84.

[119] Heydari P, Varshosaz J, Zargar Kharazi A, Karbasi S. Preparation and evaluation of poly glycerol sebacate/poly hydroxy butyrate core-shell electrospun nanofibers with sequentially release of ciprofloxacin and simvastatin in wound dressings. Polym Adv Technol 2018;29:1795-803.

[120] Li Y, Zhang C, Zhu LF, Ahmad Z, Li JS, Chang MW. Elastic antibacterial membranes comprising particulate laden fibers for wound healing applications. J Appl Polym Sci 2019;136:47105. 
[121] Felgueiras HP, Amorim MTP. Functionalization of electrospun polymeric wound dressings with antimicrobial peptides. Colloids Surf B Biointerfaces 2017;156:133-48.

[122] Kalwar K, Sun WX, Li DL, Zhang XJ, Shan D. Coaxial electrospinning of polycaprolactone@ chitosan: characterization and silver nanoparticles incorporation for antibacterial activity. React Funct Polym 2016;107:87-92.

[123] Wen S, Hu Y, Zhang Y, Huang S, Zuo Y, Min Y. Dual-functional core-shell electrospun mats with precisely controlled release of anti-inflammatory and anti-bacterial agents. Mater Sci Eng C 2019;100:514-22.

[124] Zahedi E, Esmaeili A, Eslahi N, Shokrgozar AM, Simchi A. Fabrication and characterization of core-shell electrospun fibrous mats containing medicinal herbs for wound healing and skin tissue engineering. Mar Drugs 2019;17:27.

[125] Wei Q, Xu F, Xu X, Geng X, Ye L, Zhang A, et al. The multifunctional wound dressing with core-shell structured fibers prepared by coaxial electrospinning. Front Mater Sci 2016;10:113-21.

[126] Augustine R, Zahid AA, Hasan A, Wang M, Webster TJ. CTGF loaded electrospun dual porous core-shell membrane for diabetic wound healing. Int J Nanomed 2019;14:8573-88.

[127] Fang $Y$, Zhu X, Wang N, Zhang X, Yang D, Nie J, et al. Biodegradable core-shell electrospun nanofibers based on PLA and $\gamma$-PGA for wound healing. Eur Polym J 2019;116:30-7.

[128] Choi SJ, Chattopadhyay S, Kim JJ, Kim S.J, Tuller HL, Rutledge $\mathrm{GC}$, et al. Coaxial electrospinning of $\mathrm{WO}_{3}$ nanotubes functionalized with bio-inspired Pd catalysts and their superior hydrogen sensing performance. Nanoscale 2016;8:9159-66.

[129] Ekabutr P, Klinkajon W, Sangsanoh P, Chailapakul O, Niamlang P, Khampieng T, et al. Electrospinning: a carbonized gold/graphene/pan nanofiber for high performance biosensing. Anal Methods 2018;10:874-83.

[130] Mondal K, Ali MA, Srivastava S, Malhotra BD, Sharma A. Electrospun functional micro/nanochannels embedded in porous carbon electrodes for microfluidic biosensing. Sens Actuat B Chem 2016;229:82-91.

[131] Guo Q, Liu L, Wu T, Wang Q, Wang H, Liang J, et al. Flexible and conductive titanium carbide-carbon nanofibers for high-performance glucose biosensing. Electrochim Acta 2018;281:517-24.

[132] Sapountzi E, Braiek M, Vocanson F, Chateaux JF, JaffrezicRenault N, Lagarde F. Gold nanoparticles assembly on electrospun poly(vinyl alcohol)/poly(ethyleneimine)/glucose oxidase nanofibers for ultrasensitive electrochemical glucose biosensing. Sens Actuat B Chem 2017;238:392-401.

[133] Chauhan D, Solanki PR. Hydrophilic and insoluble electrospun cellulose acetate fiber-based biosensing platform for 25-hydroxy vitamin-D detection. ACS Appl Polym Mater 2019;1:1613-23.

[134] Migliorini FL, Sanfelice RC, Mercante LA, Andre RS, Mattoso LHC, Correa DS. Urea impedimetric biosensing using electrospun nanofibers modified with zinc oxide nanoparticles. Appl Surf Sci 2018;443:18-23.

[135] Paul KB, Vanjari SRK, Singh SG. Highly sensitive electrospun multiwalled carbon nanotubes embedded zinc oxide nanowire based interface for label free biosensing. Procedia Technol 2017;27:217-8.

[136] Liu J, Niu J, Yin L, Jiang F. In situ encapsulation of laccase in nanofibers by electrospinning for development of enzyme biosensors for chlorophenol monitoring. Analyst 2011;136:4802-8.
[137] Song W, Zhao B, Wang C, Lu X. Electrospun nanofibrous materials: a versatile platform for enzyme mimicking and their sensing applications. Compos Commun 2019;12:1-13.

[138] Wang N, Burugapalli K, Wijesuriya S, Far MY, Song W, Moussy F, et al. Electrospun polyurethane-core and gelatinshell coaxial fibre coatings for miniature implantable biosensors. Biofabrication 2013;6:015002.

[139] Wang W, Li Z, Xu X, Dong B, Zhang H, Wang Z, et al. Au-doped polyacrylonitrile-polyaniline core-shell electrospun nanofibers having high field-effect mobilities. Small 2011;7:597-600.

[140] Wang Q, Wang W, Zhong L, Liu D, Cao X, Cui F. Oxygen vacancy-rich $2 \mathrm{D} / 2 \mathrm{D}$ BiOCl-g- $\mathrm{C}_{3} \mathrm{~N}_{4}$ ultrathin heterostructure nanosheets for enhanced visible-light-driven photocatalytic activity in environmental remediation. Appl Catal B Environ 2018;220:290-302.

[141] Jin M, Yu DG, Wang X, Geraldes CFGC, Williams GR, Bligh, SWA. Electrospun contrast-agent-loaded fibers for colontargeted MRI. Adv Healthc Mater 2016;5:977-85.

[142] Jin M, Yu DG, Geraldes CFGC, Williams GR, Bligh SWA. Theranostic fibers for simultaneous imaging and drug delivery. Mol Pharm 2016;13:2457-65.

[143] Yu X, Wu X, Si Y, Wang X, Yu J, Ding B. Waterproof and breathable electrospun nanofibrous membranes. Macromol Rapid Commun 2019;40:e1800931.

[144] Rehan M, Mashaly HM, Mowafi S, Abou El-Kheir A, Emam HE. Multi-functional textile design using in-situ Ag NPs incorporation into natural fabric matrix. Dyes Pigm 2015;118:9-17.

[145] Nan N, He J, You X, Sun X, Zhou Y, Qi K, et al. A stretchable, highly sensitive, and multimodal mechanical fabric sensor based on electrospun conductive nanofiber yarn for wearable electronics. Adv Mater Technol 2019;4:1800338.

[146] Miao D, Huang Z, Wang X, Yu J, Ding B. Continuous, spontaneous, and directional water transport in the trilayered fibrous membranes for functional moisture wicking textiles. Small 2018;14:e1801527.

[147] Xu Y, Sheng J, Yin X, Yu J, Ding B. Functional modification of breathable polyacrylonitrile/polyurethane/ $\mathrm{TiO}_{2}$ nanofibrous membranes with robust ultraviolet resistant and waterproof performance. J Colloid Interface Sci 2017;508:508-16.

[148] Sheng J, Xu Y, Yu J, Ding B. Robust fluorine-free superhydrophobic amino-silicone oil/ $/ \mathrm{Sio}_{2}$ modification of electrospun polyacrylonitrile membranes for waterproof-breathable application. ACS Appl Mater Interfaces 2017;9:15139-47.

[149] Zhao X, Wang S, Yin X, Yu J, Ding B. Slip-effect functional air filter for efficient purification of $\mathrm{PM}_{2.5}$. Sci Rep 2016;6:35472.

[150] Vysloužilová L, Buzgo M, Pokorný P, Chvojka J, Míčková A, Rampichová $M$, et al. Needleless coaxial electrospinning: a novel approach to mass production of coaxial nanofibers. Int J Pharm 2017;516:293-300.

[151] Chang S, Wang M, Zhang F, Liu Y, Liu X, Yu DG, et al. Sheathseparate-core nanocomposites fabricated using a trifluid electrospinning. Mater Des 2020;192:108782.

[152] Hou J, Yang J, Zheng X, Wang M, Liu Y, Yu DG. A nanofiberbased drug depot with high drug loading for sustained release. Int J Pharm 2020;583:119397.

[153] Wang K, Wang P, Wang M, Yu DG, Wan F, Bligh SWA. Comparative study of electrospun crystal-based and compositebased drug nano depots. Mater Sci Eng C 2020;113:110988. 